\title{
Uncertainty Estimation by Monte Carlo Simulation Applied to Life Cycle Inventory of Cordless Phones and Microscale Metallization Processes
}

\author{
Anders S. G. Andræ, Patrik Möller, Johan Anderson, and Johan Liu, Senior Member, IEEE
}

\begin{abstract}
This paper focuses on uncertainty analysis, that is, how the input data uncertainty affects the output data uncertainty in small but realistic product systems. The motivation for the study is to apply the Monte Carlo simulation for uncertainty estimation in life cycle inventory and environmental assessment of microelectronics applications. The present paper addresses the question whether there is an environmental advantage of using digital enhanced cordless telecommunications (DECT) phones instead of global system for mobile (GSM) phones in offices. This paper also addresses the environmental compatibility of electrochemical pattern replication (ECPR) compared to classical photolithography-based microscale metallization (CL) for pattern transfer. Both environmental assessments in this paper consider electricity consumption and $\mathrm{CO}_{2}$ emissions and the projects undertaken are two comparative studies of DECT phone/GSM phone and ECPR/CL, respectively. The research method used was probabilistic uncertainty modeling with a limited number of inventory parameters used in the MATLAB tool. For the DECT/GSM study the results reflects the longer DECT technical life which is an environmental advantage. For the electrochemical pattern replication (ECPR)/classical photolithography based microscale metallization (CL) study the results reflects the fewer number of process steps and the lower electricity consumption needed by the ECPR to reach the functional unit. The difference in results is large enough to be able to draw conclusions, as the processes, having the highest electricity consumption within the system boundaries have been determined. Based on an earlier work, a straightforward method to include uncertainty for input life cycle inventory data is used to quantify the influence of realistic errors for input data in two microelectronic applications. The conclusion is that the ECPR technology is more electricity efficient than $C L$ in producing one layer of copper on a silicon wafer having a diameter of $20.32 \mathrm{~cm}$. Furthermore, the longer technical life of a cordless DECT phone is reflected in an electricity/ $\mathrm{CO}_{2}$ comparison with a GSM phone, if office use is considered. Reasonable uncertainty intervals, used for the input life cycle inventory data for the studied DECT/GSM and ECPR/CL system, does affect the outcome of calculation of emission of $\mathrm{CO}_{2}$, but not to the degree that conclusions are not valid. Different uncertainty intervals and probability distributions could apply for different types of data and the interrelated input
\end{abstract}

Manuscript received May 4, 2004. This work was supported by EPROPER (a Swedish National research school for graduate students in the area of electronics production and packaging).

A. S. G. Andræ, J. Anderson are with the SMIT, Sino-Swedish Microsystems Integration and Technology Centre and the Department of Microtechnology and Nanoscience, Chalmers University of Technology, Gothenburg, SE-41296 Göteborg, Sweden (e-mail: anders.andrae@mc2.chalmers.se).

P. Möller is with the Department of Microelectronics and Information Technology, Laboratory of Solid State Devices, Device Technology, Royal Institute of Technology (KTH), Stockholm, Sweden

J. Liu is with the Department of Microtechnology and Nanoscience, Chalmers University of Technology, Gothenburg, SE-41296 Göteborg, Sweden, and also with the SMIT Center, Shangai University, Shangai 200072, China.

Digital Object Identifier 10.1109/TEPM.2004.843163 data dependencies should be investigated. Today there exist very few life cycle inventory (LCI) data with the range of uncertainty for input and output elements. It must be emphasized that the upcoming LCI databases should have standard deviation characterized LCI data just as the Swiss ecoinvent LCI database. More inventory parameters and probability distributions characteristic for microsystems could be included and error analysis should be applied to future life inventory methodology, especially for future packaging concepts such as system-in-a-package and system-on-a-chip comparisons.

Index Terms-Classical photolithography metallization, $\mathrm{CO}_{2}$, digital enhanced cordless telecommunications (DECT), electrochemical pattern replication (ECPR), global system for mobile (GSM), life cycle inventory, Monte Carlo simulation, uncertainty analysis.

\section{INTRODUCTION}

$\mathbf{E}$ NVIRONMENTAL life cycle inventory and assessment is a method which is used to quantify the environmental load and effects associated with a product, process or service. Life cycle oriented assessment demands a lot of data and information that is not easily obtained or at times not ascertained. Therefore, collecting data with high quality is time consuming but the author has previously developed a generic life cycle inventory (LCI) data collection method for electronic products [1]. The result of an LCI and LCA is limited by the accuracy of the input data and it is essential to get understanding of the quality of the LCI data in order to determine if two comparative results are valid. So far, the LCA case studies published frequently do not take the LCI data uncertainty into quantitative concern [2]. The issue of uncertainty for LCI data and its causes has been known for a long time as an important research topic, but not until the last few years research has been carried out in this field. The uncertainty in LCA calculations rises rapidly when characterization and weighting is included [3]. Error analysis can roughly be divided into three areas; gravity analysis, uncertainty analysis, and sensitivity analysis [2]. This paper focuses on uncertainty analysis in which it is modeled how the input data uncertainty affects the output data uncertainty in small but realistic product systems. The ISO standard for LCA [13] defines and describes the term product system in more detail.

In the uncertainty analysis, an uncertainty is set to the input data to see how the output data is affected. The objective of this study is to introduce a straightforward way to include uncertainty estimations in LCI of microelectronic products and processes. Monte Carlo simulation was used for the uncertainty calculations, as it is a method for solving problems which cannot 
be exactly unraveled but has to be worked out using calculations performed on a set of random variables. The MATLAB code is provided in the Appendix, Section IX, enabling another user to reproduce the calculations. The procedure developed was applied to a comparison between two types of mobile phones, a DECT phone compared to a GSM phone, and a comparison between a classical photolithographic process and a novel process. The latter is developed to manufacture micro- and nano structures in conducting materials, based on the patented electrochemically pattern replication process (ECPR) technology [4].

\section{EARLIER STUDIES AND APPROACHES}

Some problems are easy to formulate but not so easy to solve. One of those problems can be formulated: Is A better than B seen from an environmental point of view? The problem is often to say by which probability we can say that A is better than B. Often organizations have a clue about which environmental properties their products have but do not know enough about the methods or tools to generate a number with known uncertainty quantifications.

Probability theory is the most common quantitative format for describing uncertainty and is widely understood. Despite of this, the inclusion of uncertainty analysis is not common practice in LCI. It is probably due to the many different types of uncertainty attached to the LCI data, such as parameter uncertainty, model uncertainty, uncertainty due to choices, spatial variability, temporal variability, variability between sources and objects because of using different technologies and the number of input data elements. In fact, only a few percent of published environmental life cycle assessment (LCA) studies have included quantification of uncertainty. [2], [11]. Unfortunately, the tradeoff between model and data uncertainty is often unquantified and therefore difficult to evaluate [5].

Monte Carlo simulation (MCS) is a technique for finding statistical information about a value resulting from calculations performed on a set of random variables. For a large number of trials, the frequency distribution of the calculated results should approximate the true probability distribution of the value of interest [6]. The variant of MCS used in this paper is described in Section III.

Steen [3] emphasizes the appropriateness of the log-normal distribution as no negative numerical values can be allowed for life cycle inventory data. Sandborn [7] used the triangular distribution because both the maximum and minimum values produced by the distribution are controllable. Kennedy et al. [8] recommend beta distributions for inventory but is it not clear how accurate the choice of distribution has to be.

Ciroth [9], May [2], Steen [3], Maurice [10], Sonnemann [11], and Heijungs [12] have done work in the area of quantification of uncertainty in traditional life cycle assessment (LCA). Heijungs [12] proposed a method for mathematical description of how the propagation of uncertainties in input data influences the uncertainty for output data, mainly focusing on inventory data. Steen [3] generated a method for the calculation of probability and sensitivity figures in a general way for LCA. It has been used in this paper as it was judged to be sufficiently accurate seen in the light of the aim of the study.
The common denominator for earlier approaches is that although they all differ in technique all suggest or use MCS which combine sets of data deviating randomly within specified margins. This paper is influenced by their research as the methodology used and developed in this work estimates the quantity of the variance for two microelectronics applications.

This paper follows the recommendation of Sonnemann et al. [11] which pointed out the need for uncertainty assessment studies by MCS for processes other than electricity production.

Deliberately, only one indicator parameter [13] was chosen for the calculations, as the uncertainty was judged too large for most characterization and weighting indices currently used in LCA. $\mathrm{CO}_{2}$ was chosen as indicator for this research as it is a global emission and the electronics industry is a global industry. To the authors' knowledge, Ram et al. [14] and Schäfer [15] are the only authors who have compared cordless phones with cellular from an environmental standpoint but uncertainty analysis was not included. The result of Ram et al. [14] indicated that the mobile phones had a lower environmental impact per piece than cordless phones due to lower weight and reduced energy consumption but the present study has a different scope and electricity consumption calculation procedure. No environmental assessment of photolithographic processes was found in the literature and so far no MCS has been applied to the systems studied in this paper. The motivation for the study was to apply the MCS for uncertainty estimation in life cycle inventory and environmental assessment of microelectronics applications and another aim was to find out the presupposed environmental compatibility of the novel ECPR process technology.

The main questions addressed in this paper are as follows.

- Which uncertainty is allowed for the input data to get a certain standard deviation for the final result?

- $\quad$ By which probability can it be stated that one alternative is better than the other?

- Which input data influences the result the most?

These questions will be answered using four product systems, a DECT phone compared to a GSM phone and the electrochemical pattern replication (ECPR) versus the classical photolithography based microscale metallization (CL).

\section{METHOD}

In this section, the uncertainty analysis procedure will be performed through the following steps.

1. Choose an indicator parameter, e.g., $\mathrm{CO}_{2}$ emission to air, as basis for the comparison. Calculating a result e.g., using an LCA software tool makes the choice. Sonnemann [11] proposed to use the EcoIndicator 99 weighting method [16] to choose indicator parameters, but in this paper $\mathrm{CO}_{2}$ was chosen from global warming potential (GWP).

2. Calculate a base line result of emissions of $\mathrm{CO}_{2}$ for the alternatives which are to be compared.

3. Use MATLAB plots to test which standard deviations for the lognormal distribution that corresponds to guessed maximum and minimum values representing the fluctuation of input parameters influencing the outcome of the $\mathrm{CO}_{2}$-emission calculation. 


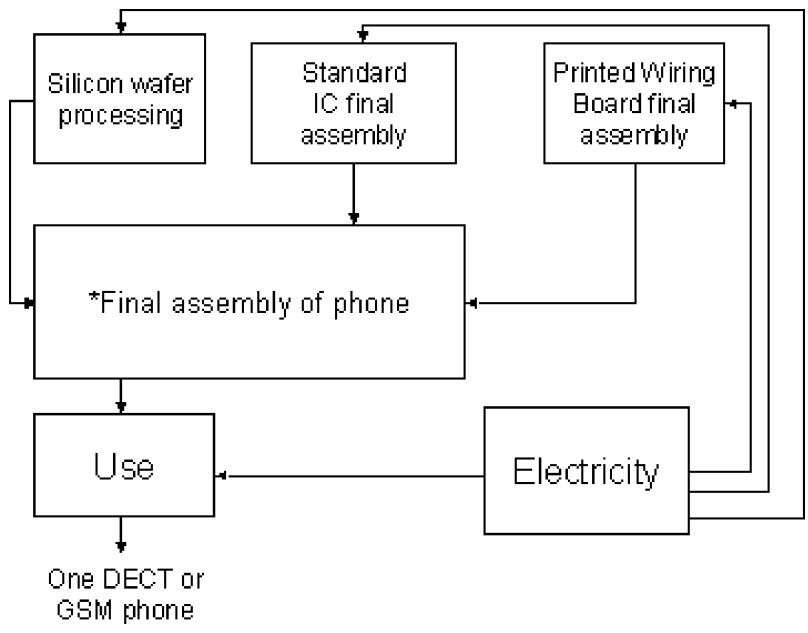

Fig. 1. System boundaries for the comparison between DECT and GSM phones. The final assembly process of the DECT or GSM phone is not included. The silicon wafer processing is in reality located before the Standard IC final assembly.

4. Generate, e.g., 1000 random variables from the log-normal distribution for the input parameters influencing the emissions of $\mathrm{CO}_{2}$.

5. Calculate the result which is the probability for which one alternative is better than the other. The MATLAB code to reproduce Figs. 6 and 7 is given in Appendix, Section IX.

6. Calculate for which input data element the output is most sensitive. Newton's method [17] was used in MATLAB to reproduce Tables III and IV. The MATLAB code to calculate the critical error factors is given in the Appendix , Section IX.

\section{A. Application Example I: Mobile Phones in Office Environment, DECT Versus GSM}

This comparison estimates which type of telephone is better to use in office environments, hypothesising the DECT phone is superior due to its longer life.

A comparison between two types of mobile phones, a cordless digital enhanced cordless telecommunications (DECT) phone and a cellular global system for mobile (GSM) phone, was made. To make the comparison as time efficient and simple as possible, some basic facts were collected. Seen from a greenhouse gas perspective, earlier life cycle assessment studies indicate that some electrical hardware components are more important than others. [18], [19]. Thus, it was decided to include the final assembly process of integrated circuits (standard IC), the wafer processing of silicon chips and the final assembly process of the printed wiring boards (PWB) as well as the unit process for electricity production from cradle-to-gate. Both phones apply to the flow diagram and system boundaries shown in Fig. 1.

The two products can be used in the office environment and have a comparable functional unit which is defined as one phone in use during eight years.

Included in the functional unit is a phone usage within the office and not far outside the office, which would have been possible for the GSM phone. No uncertainty is assumed in the functional unit.
TABLE I

COLlected DATA FOR CALCUlATIONS; DECT AND GSM

\begin{tabular}{|c|c|c|}
\hline Parameter & DECT & GSM \\
\hline Chip surface ${ }^{1}\left(\mathrm{~mm}^{2}\right)$ & 200 & 112.5 \\
\hline $\begin{array}{l}\text { Weight microcircuits } \\
(\mathrm{g})\end{array}$ & 1.536 & 1.398 \\
\hline PWB area $\left(\mathrm{m}^{2}\right)$ & 0.005978 & 0.00429 \\
\hline Number of layers & 6 & 6 \\
\hline PWB $\left(\mathrm{m}^{2} *\right.$ layers $)$ & 0.035 & 0.02574 \\
\hline Weight phone (g) & 140 & 105 \\
\hline Electricity $\left(\mathrm{g} \mathrm{CO}_{2} / \mathrm{MJ}\right)$ & 132 & 132 \\
\hline Electricity $(\mathrm{MJ} / \mathrm{g} \mathrm{IC})$ & 0.9453 & 0.9453 \\
\hline $\begin{array}{c}\text { Electricity }\left(\mathrm{MJ} / \mathrm{mm}^{2}\right. \\
\text { Silicon wafer) }\end{array}$ & 0.0136 & 0.0136 \\
\hline Speech time $(\mathrm{h})$ & 8 & 1 to 6 \\
\hline Standby time (h) & 80 & 60 to 220 \\
\hline Battery capacity (Ah) & 0.55 & 0.6 \\
\hline $\begin{array}{c}\text { Electricity } \\
\text { consumption use phase } \\
(\mathrm{kJ} / \text { year })\end{array}$ & $862.488^{2}$ & $892.569^{3}$ \\
\hline Working days per year & 220 & 220 \\
\hline Voltage (V) & 4.8 & 3.6 \\
\hline
\end{tabular}

1. Surface of Processed Silicon

2.

$$
\begin{aligned}
\mathrm{W}= & \{\text { speech time }+ \text { standby time }\} \\
= & \frac{1}{24} \mathrm{H} * 0.55 \mathrm{AH} * \frac{1}{8} \mathrm{H} * 4.8 \mathrm{~V} * 24 \mathrm{H} \\
& * 220 \frac{\mathrm{DAYS}}{\mathrm{YEAR}} * 60 \frac{\mathrm{MIN}}{\mathrm{SEC}} * 60 \frac{\mathrm{SEC}}{\mathrm{MIN}} \\
& +\frac{23}{24} \mathrm{H} * 0.55 \mathrm{AH} * \frac{1}{80} \mathrm{H} * 4.8 \mathrm{~V} * 24 \mathrm{H} \\
& * 220 \frac{\mathrm{DAYS}}{\mathrm{YEAR}} * 60 \frac{\mathrm{MIN}}{\mathrm{SEC}} * 60 \frac{\mathrm{SEC}}{\mathrm{MIN}} \\
= & 862488 \frac{\mathrm{J}}{\mathrm{YEAR}}
\end{aligned}
$$

6.89 MJ for eight years.

$$
\begin{aligned}
\mathrm{W}= & \{\text { speech time }+ \text { standby time }\} \\
= & \frac{1}{24} \mathrm{H} *+0.6 \mathrm{AH} * \frac{1}{2.9} \mathrm{H} * 3.6 \mathrm{~V} * 24 \mathrm{H} \\
& * 220 \frac{\mathrm{DAYS}}{\mathrm{YEAR}} * 60 \frac{\mathrm{MIN}}{\mathrm{SEC}} * 60 \frac{\mathrm{SEC}}{\mathrm{MIN}} \\
& +\frac{23}{24} \mathrm{H} * 0.6 \mathrm{AH} * \frac{1}{130} \mathrm{H} * 3.6 \mathrm{~V} * 24 \mathrm{H} \\
& * 220 \frac{\mathrm{DAYS}}{\mathrm{YEAR}} * 60 \frac{\mathrm{MIN}}{\mathrm{SEC}} * 60 \frac{\mathrm{SEC}}{\mathrm{MIN}} \\
= & 892569 \frac{\mathrm{J}}{\mathrm{YEAR}}
\end{aligned}
$$

$7.14 \mathrm{MJ}$ for eight years.

$$
\mathrm{W}=\text { ELECTRICAL ENERGY. }
$$

The data collected for the two phones is summarized in Table I. The differences between the phones are: the use phase electricity consumption, the weight of the phone, the weight of the microcircuits (standard IC), the PWB area, and the silicon chip surface.

The microcircuits were weighed and the chip surfaces were estimated. The areas of the printed wiring boards and the numbers of layers were measured. The data for battery capacity, speech time, standby time, voltage and weight were taken from technical data sheets. [20], [21].

\section{B. Application Example II: Electrochemical Pattern Replication Versus Classical Photolithography-Based Microscale Metallization}

Pattern transfer by photolithography is important in the electronics industry to produce many electronic components 
on a small area. The functional unit in the comparison between classical photolithography-based microscale metallization (CL) and electrochemical pattern replication (ECPR) is to build up one layer of $3 \mu \mathrm{m}$ copper on a silicon wafer having a diameter of $20.32 \mathrm{~cm}$ in an additive process, respectively. Currently in industry, photolithography combined with chemical etching/plating/dry etching/vaporization (CL) is used for pattern transfer. Each substrate (the silicon wafer) subject of patterning has to undergo a number of process steps. A typical additive photolithographic-based process for metallization of silicon wafers, used for advanced packaging applications, consists of the following nine process steps.

1. A photo-resist is applied to the substrate by spin coating.

2. The photo-resist may have to be treated with chemicals to become smoother.

3. The photo-resist is soft-baked in an oven and then cooled off.

4. The photo-resist is exposed by UV-light through a photo mask letting the light in according to a certain pattern.

5. The photo-resist is prebaked in an oven thereafter cooled off.

6. The photo-resist is developed in a liquid bath in which the photo-resist gets a pattern defined by the exposure.

7. Hard-baking in an oven makes the photo-resist stable after it must cool off.

8. The substrate is plated using $\mathrm{CuSO}_{4}$ to transfer the defined pattern to the active material. The photo-resist protects a certain area that thus is not removed/plated and structures on the substrate are received.

9. The photo-resist is removed with different chemicals (stripping) providing the finished product, a $20.32 \mathrm{~cm}$ diameter silicon wafer having a $3 \mu \mathrm{m}$ layer of copper, is ready.

Using a process (ECPR) developed at Lund Institute of Technology (LTH) and the Royal Institute of Technology (KTH), Sweden, the pattern definition and pattern transfer is performed in one single process step. The ECPR has a total processing time of 30-300 s per copper layer compared to $3600-7200 \mathrm{~s}$ for CL [22]. A unique template with the desired pattern is used for direct electrochemical replication of the patterned metal layer (ECPR). For an additive sequence, the ECPR process has the following steps.

1. A well-defined amount of copper material is deposited in the master electrode (template).

2. The master electrode and the substrate are pressed together and forms local plating cells. The pattern is replicated on the substrate as the external plating voltage is applied. The structures have been additively copied to the substrate providing the finished product.

The industrial use of the additive process was chosen as it is judged to be the most common. Since the sputtering of a seed layer step and a final chemical seed etch step is needed for both traditional processing (CL) and ECPR it is not included in this comparison. The system boundaries for the $\mathrm{CL}$ and the ECPR are shown in Figs. 2 and 3, respectively.

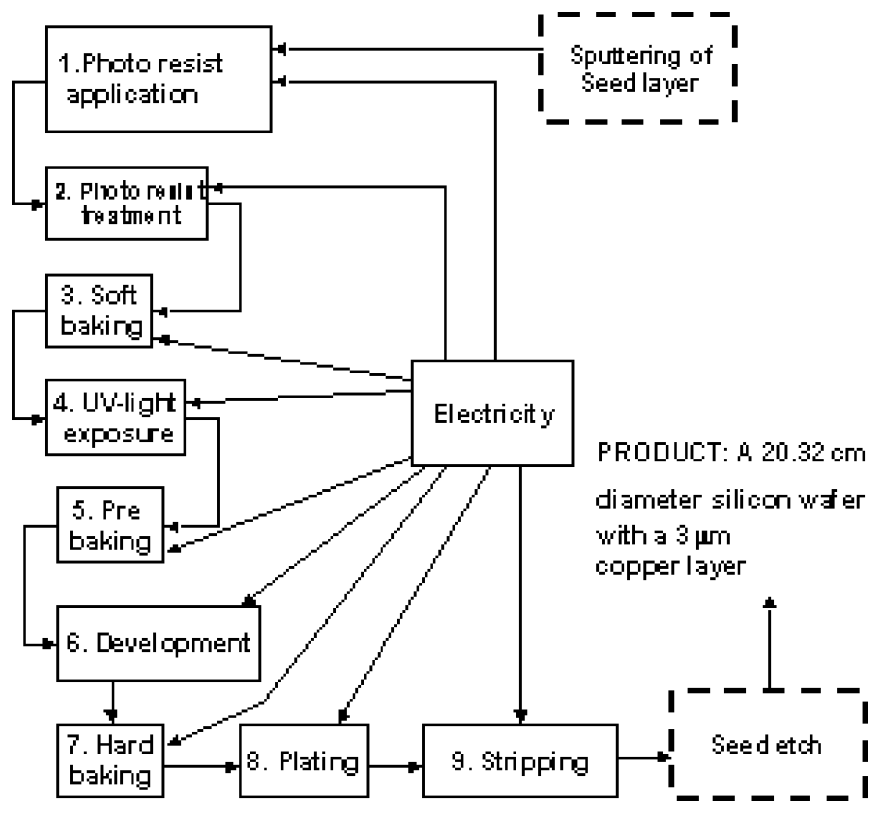

Fig. 2. System boundaries for CL.

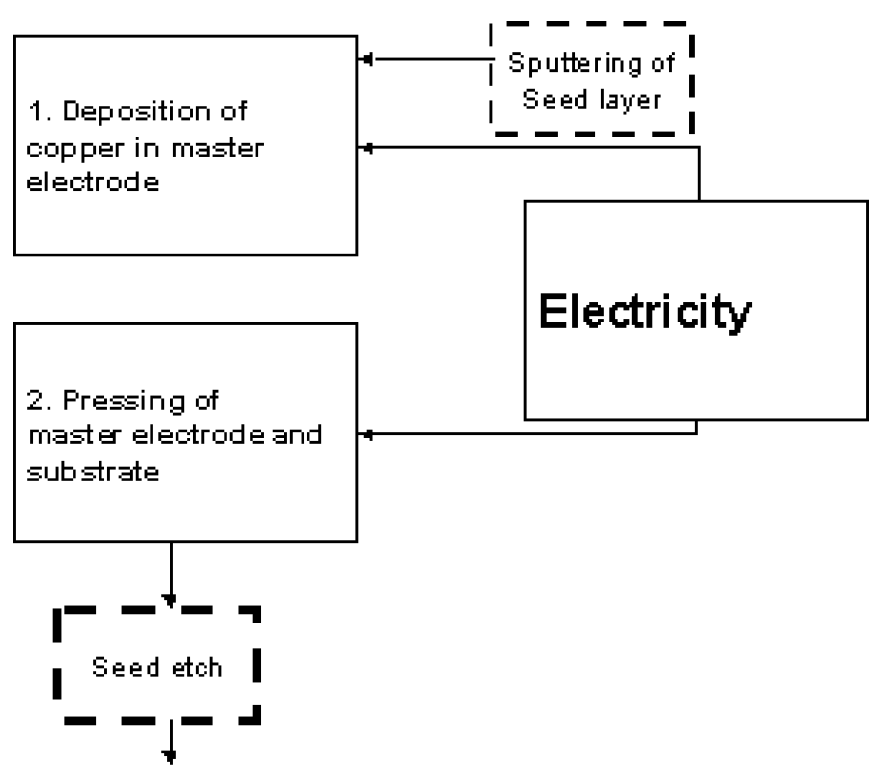

PRO DIJCT: A 2032 om dameter silicon wafer

with a $3 \mu \mathrm{m}$

oopper layer

Fig. 3. System boundaries for ECPR.

In Table II, the values for the application examples I and II are summarized, where

A $=$ electricity consumption (MJ) at printed wiring board final assembly per $\mathrm{m}^{2} *$ layer;

$\mathrm{B}=\mathrm{CO}_{2}$ emission $(\mathrm{g})$ when $1 \mathrm{MJ}$ electricity is produced, B is later notated B1, B2, S, and R to be able to calculate the relative sensitivity of $\mathrm{B}$;

$\mathrm{C}=$ = electricity consumption (MJ) IC final assembly;

$\mathrm{D} \quad=$ electricity consumption (MJ) IC wafer processing per $\mathrm{mm}^{2}$;

$\mathrm{E} \quad=$ weight of ICs $(\mathrm{g})$ for the DECT phone;

$\mathrm{F}=$ number of $\mathrm{m}^{2} *$ layers in the DECT phone; 
TABLE II

VALUES AND DISTRIBUTIONS

\begin{tabular}{|c|c|c|c|c|c|}
\hline Parameter & Best estimate & $\begin{array}{c}\text { Maximum } \\
\text { and minimum } \\
\text { values }\end{array}$ & $\begin{array}{l}\text { Distribution } \\
\text { function }\end{array}$ & $\begin{array}{c}\text { Distribution } \\
\text { parameter } \\
\text { type }\end{array}$ & $\begin{array}{c}\text { Distribution } \\
\text { parameter value } \\
\text { (error factor) }\end{array}$ \\
\hline CL1 & 6 & $4.5-8$ & Log-normal & $\begin{array}{r}\text { Standard } \\
\text { deviation }\end{array}$ & 1.1 \\
\hline CL2 & 12 & $9-16.5$ & Log-normal & $\begin{array}{l}\text { Standard } \\
\text { deviation }\end{array}$ & 1.1 \\
\hline CL3 & 300 & $220-400$ & Log-normal & $\begin{array}{l}\text { Standard } \\
\text { deviation }\end{array}$ & 1.1 \\
\hline CL4 & 20 & $13-29$ & Log-normal & $\begin{array}{l}\text { Standard } \\
\text { deviation }\end{array}$ & 1.1 \\
\hline CL5 & 240 & $160-330$ & Log-normal & $\begin{array}{r}\text { Standard } \\
\text { deviation }\end{array}$ & 1.1 \\
\hline CL6 & 60 & $44-82$ & Log-normal & $\begin{array}{l}\text { Standard } \\
\text { deviation }\end{array}$ & 1.1 \\
\hline CL7 & 900 & $700-1200$ & Log-normal & $\begin{array}{l}\text { Standard } \\
\text { deviation }\end{array}$ & 1.1 \\
\hline CL8 & 15 & $11-21$ & Log-normal & $\begin{array}{l}\text { Standard } \\
\text { deviation }\end{array}$ & 1.1 \\
\hline CL9 & 45 & $31-62$ & Log-normal & $\begin{array}{l}\text { Standard } \\
\text { deviation }\end{array}$ & 1.1 \\
\hline $\mathrm{S}$ & 0.132 & $0.05-0.31$ & Log-normal & $\begin{array}{l}\text { Standard } \\
\text { deviation }\end{array}$ & 1.4 \\
\hline $\mathrm{R}$ & 0.132 & $0.05-0.31$ & Log-normal & $\begin{array}{l}\text { Standard } \\
\text { deviation }\end{array}$ & 1.4 \\
\hline ECPR1 & 11.5 & $11-21$ & Log-normal & $\begin{array}{l}\text { Standard } \\
\text { deviation }\end{array}$ & 1.1 \\
\hline ECPR2 & 11.5 & $11-21$ & Log-normal & $\begin{array}{l}\text { Standard } \\
\text { deviation }\end{array}$ & 1.1 \\
\hline A & 51.696 & $30-90$ & Log-normal & $\begin{array}{l}\text { Standard } \\
\text { deviation }\end{array}$ & 1.2 \\
\hline B & 132 & $50-310$ & Log-normal & $\begin{array}{l}\text { Standard } \\
\text { deviation }\end{array}$ & 1.4 \\
\hline $\mathrm{C}$ & 0.9453 & $0.45-1.9$ & Log-normal & $\begin{array}{l}\text { Standard } \\
\text { deviation }\end{array}$ & 1.3 \\
\hline $\mathrm{D}$ & 0.0136 & $0.005-0.048$ & Log-normal & $\begin{array}{l}\text { Standard } \\
\text { deviation }\end{array}$ & 1.5 \\
\hline $\mathrm{E}$ & 1.536 & $1.37-1.67$ & Log-normal & $\begin{array}{l}\text { Standard } \\
\text { deviation }\end{array}$ & 1.03 \\
\hline $\mathrm{F}$ & 0.035 & $0.034-0.036$ & Log-normal & $\begin{array}{l}\text { Standard } \\
\text { deviation }\end{array}$ & 1.01 \\
\hline G & 200 & $100-390$ & Log-normal & $\begin{array}{l}\text { Standard } \\
\text { deviation }\end{array}$ & 1.2 \\
\hline $\mathrm{H} 1$ & 1 & & & & 1 \\
\hline $\mathrm{H} 2$ & 23 & & & & 1 \\
\hline $\mathrm{H} 3$ & 0.55 & & & & 1 \\
\hline $\mathrm{H} 4$ & 8 & & & & 1 \\
\hline $\mathrm{H} 5$ & 4.8 & & & & 1 \\
\hline H6 & 80 & & & & 1 \\
\hline $\mathrm{Y}$ & $152.064 \mathrm{e} 6$ & & & & 1 \\
\hline I & 5.56 & $5-6$ & Log-normal & $\begin{array}{l}\text { Standard } \\
\text { deviation }\end{array}$ & 1.03 \\
\hline $\mathrm{J}$ & 0.103 & $0.1-0.106$ & Log-normal & $\begin{array}{l}\text { Standard } \\
\text { deviation }\end{array}$ & 1.01 \\
\hline $\mathrm{K}$ & 450 & $260-750$ & Log-normal & $\begin{array}{r}\text { Standard } \\
\text { deviation }\end{array}$ & 1.2 \\
\hline L1 & 0.6 & & & & 1 \\
\hline $\mathrm{L} 2$ & 2.9 & $1-6$ & Log-normal & $\begin{array}{l}\text { Standard } \\
\text { deviation }\end{array}$ & 1.25 \\
\hline 3 & 3.6 & & & & 1 \\
\hline L4 & 130 & $60-220$ & Log-normal & $\begin{array}{l}\text { Standard } \\
\text { deviation }\end{array}$ & 1.2 \\
\hline
\end{tabular}

$=$ number of $\mathrm{mm}^{2} \mathrm{Si}$ in DECT;

$=$ speech hours per day;

$=$ idle hours per day;

= battery capacity (Ah) for DECT;

$=$ maximum speech time $(\mathrm{h})$ for the DECT;
H5 $\quad=$ voltage $(\mathrm{V})$ for the DECT phone;

$\mathrm{H} 6$ = maximum standby time (h) for the DECT phone;

$\mathrm{Y} \quad=$ seconds per 220 days during eight years;

I = weight of ICs ( $\mathrm{g}$ ) for GSM phone; 


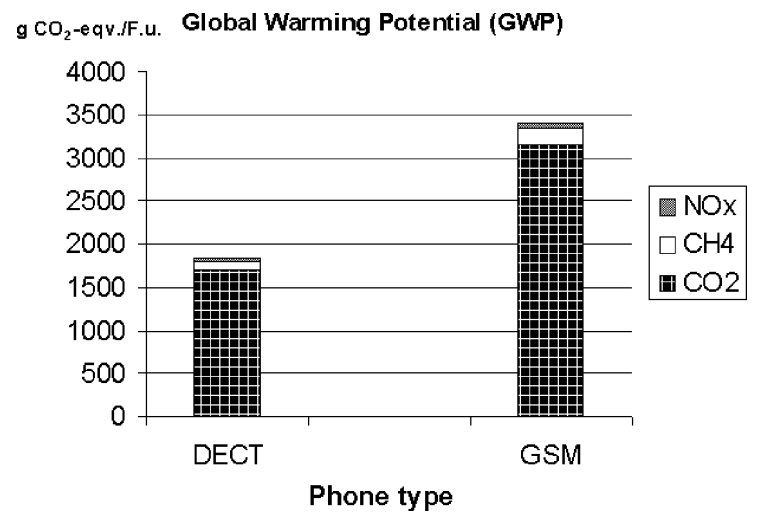

Fig. 4. Total GWP for DECT and GSM within system boundaries. The GSM phone is assumed to have a service life of two years.

$\begin{array}{ll}\mathrm{J} & =\text { number of } \mathrm{m}^{2} * \text { layers in the GSM phone; } \\ \mathrm{K} & =\text { number of } \mathrm{mm}^{2} \mathrm{Si} \text { in GSM; } \\ \mathrm{L} 1 & =\text { battery capacity (Ah) for GSM; } \\ \mathrm{L} 2 & =\text { maximum speech time (h) for the GSM; } \\ \mathrm{L} 3 & =\text { voltage (V) for the GSM phone; } \\ \mathrm{L} 4 & =\text { maximum standby time (h) for the GSM phone; } \\ \mathrm{CL} 1 & \text { = electricity consumption (kJ) for CL photo resist } \\ & \text { application; }\end{array}$

CL2 = electricity consumption ( $\mathrm{kJ}$ ) CL photo resist treatment;

CL3 = electricity consumption (kJ) for CL soft baking;

CL4 = electricity consumption (kJ) for CL UV light exposure;

CL5 = electricity consumption ( $\mathrm{kJ}$ ) for CL prebaking;

CL6 = electricity consumption (kJ) CL development;

CL7 = electricity consumption (kJ) for hard baking;

CL8 = electricity consumption ( $\mathrm{kJ}$ ) for CL plating;

CL9 = electricity consumption (kJ) CL stripping;

ECPR1 = electricity consumption in $(\mathrm{kJ})$ for ECPR $\mathrm{Cu}$ deposition on master;

ECPR2 = electricity consumption in $(\mathrm{kJ})$ for ECPR pressing of master and substrate.

\section{CAlculations and Results}

The process trees for the four product systems were built up in the LCA software EcoLab 5.3.3 [23], and the electricity figures were put into the database.

The total results from global warming potential (GWP) for DECT and GSM phones is shown in Fig. 4 and for the lithographic processes in Fig. 5.

As shown in Figs. 4 and 5, $\mathrm{CO}_{2}$ constitute more than $90 \%$ of the GWP impacts and could therefore be used for further Monte Carlo simulations.

The amount of $\mathrm{CO}_{2}$ emitted to air from the DECT phone, $\mathrm{N}$, is calculated with the following formula:

$\mathrm{N}=\mathrm{F} . * \mathrm{~A} . * \mathrm{~B} 1+\mathrm{E} . * \mathrm{C} . * \mathrm{~B} 1+\mathrm{G} . * \mathrm{D} . * \mathrm{~B} 1$

$+\frac{\left(\frac{\mathrm{H} 1 .}{24 .} * \mathrm{H} 3 . * \frac{1 .}{\mathrm{H} 4 .} * \mathrm{H} 5 . * \mathrm{Y} 1+\frac{\mathrm{H} 2 .}{24 .} * \mathrm{H} 3 . * \frac{1}{\mathrm{H} 6 .} * \mathrm{H} 5 . * \mathrm{Y} 2\right) .}{1 \mathrm{e} 6 . * \mathrm{~B} 1}$

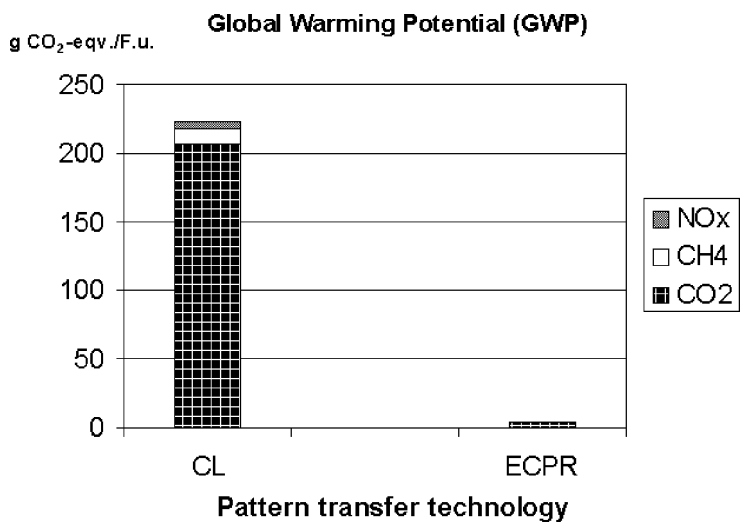

Fig. 5. Total GWP for classical photolithography based microscale metallization (CL) and ECPR within system boundaries.

and the amount of $\mathrm{CO}_{2}$ emitted to air from the GSM phone, $\mathrm{O}$, is calculated with the following formula:

$\mathrm{O}=\mathrm{J} . * \mathrm{~A} . * \mathrm{~B} 2+\mathrm{I} . * \mathrm{C} . * \mathrm{~B} 2+\mathrm{K} . * \mathrm{D} . * \mathrm{~B} 2$
$+\frac{\left(\frac{\mathrm{H} 1}{24 .} * \mathrm{~L} 1 . * \frac{1 .}{\mathrm{L} 2 .} * \mathrm{~L} 3 . * \mathrm{Y} 1+\frac{\mathrm{H} 2 .}{24 .} * \mathrm{~L} 1 . * \frac{1}{\mathrm{~L} 4 .} * \mathrm{~L} 3 . * \mathrm{Y} 2\right) .}{1 \mathrm{e} 6 . * \mathrm{~B} 2}$.

For the calculation of $\mathrm{CO}_{2}$ emitted to air from the ECPR, the following formula is used:

$$
\mathrm{V}=\mathrm{ECPR} 1 * \mathrm{R}+\mathrm{ECPR} 2 * \mathrm{R}
$$

and for the amount of $\mathrm{CO}_{2}$ emitted to air from the CL, the following formula is used:

$\mathrm{U}=\mathrm{CL} 1 * \mathrm{~S}+\mathrm{CL} 2 * \mathrm{~S}+\mathrm{CL} 3 * \mathrm{~S}+\mathrm{CL} 4 * \mathrm{~S}+\mathrm{CL} 5 * \mathrm{~S}$

$$
+\mathrm{CL} 6 * \mathrm{~S}+\mathrm{CL} 7 * \mathrm{~S}+\mathrm{CL} 8 * \mathrm{~S}+\mathrm{CL} 9 * \mathrm{~S} .
$$

$\mathrm{Z}$ gives the difference between the DECT and the GSM phones

$$
\begin{aligned}
\mathrm{Z}= & \mathrm{F} . * \mathrm{~A} . * \mathrm{~B} 1-\mathrm{J} . * \mathrm{~A} . * \mathrm{~B} 2+\mathrm{E} . * \mathrm{C} . * \mathrm{~B} 1 \\
& -\mathrm{I} . * \mathrm{C} . * \mathrm{~B} 2+\mathrm{G} . * \mathrm{D} . * \mathrm{~B} 1-\mathrm{K} . * \mathrm{D} . * \mathrm{~B} 2 \\
& +\frac{\left(\frac{\mathrm{H} 1 .}{24 .} * \mathrm{H} 3 . * \frac{1 .}{\mathrm{H} 4} * \mathrm{H} 5 . * \mathrm{Y} 1+\frac{\mathrm{H} 2 .}{24 .} * \mathrm{H} 3 . * \frac{1 .}{\mathrm{H} 6 .} * \mathrm{H} 5 . * \mathrm{Y} 2\right) .}{1 \mathrm{e} 6 . * \mathrm{~B} 1} \\
& -\frac{\left(\frac{\mathrm{H} 1 .}{24 .} * \mathrm{~L} 1 . * \frac{1 .}{\mathrm{L} 2 .} * \mathrm{~L} 3 . * \mathrm{Y} 1+\frac{\mathrm{H} 2}{24 .} * \mathrm{~L} 1 . * \frac{1 .}{\mathrm{L} 4 .} * \mathrm{~L} 3 . * \mathrm{Y} 2\right) .}{1 \mathrm{e} 6 . * \mathrm{~B} 2} .
\end{aligned}
$$

The best estimate for $\mathrm{N}$ is $1700 \mathrm{~g} \mathrm{CO}_{2}$ and for $\mathrm{O}$ is 3147 this making $\mathrm{Z}=\mathrm{N}-\mathrm{O}$ equal to $-1447 \mathrm{~g} \mathrm{CO}_{2}$. T gives the difference between the ECPR and the

$$
\begin{aligned}
\mathrm{CL}: \mathrm{T}= & \mathrm{ECPR} 1 * \mathrm{R}+\mathrm{ECPR} 2 * \mathrm{R}-\mathrm{CL} 1 * \mathrm{~S}-\mathrm{CL} 2 * \mathrm{~S} \\
& -\mathrm{CL} 3 * \mathrm{~S}-\mathrm{CL} 4 * \mathrm{~S}-\mathrm{CL} 5 * \mathrm{~S}-\mathrm{CL} 6 * \mathrm{~S} \\
& -\mathrm{CL} 7 * \mathrm{~S}-\mathrm{CL} 8 * \mathrm{~S}-\mathrm{CL} 9 * \mathrm{~S} .
\end{aligned}
$$

The best estimate for $\mathrm{V}$ is $3.96 \mathrm{~g} \mathrm{CO}_{2}$ and for $\mathrm{U} 210.93$ making $\mathrm{T}=\mathrm{V}-\mathrm{U}$ equal to

$$
\begin{array}{r}
0.132 *(15+15-6-12-300-20-240-60-900-15-45) \\
=-206.97 \mathrm{~g} \mathrm{CO}_{2} .
\end{array}
$$

The result shows a clear advantage for the ECPR process. It could be determined, within the system boundary and with the input data uncertainty according to Table II, that the probability of DECT being better than GSM is 90\%, as shown by Fig. 6 . This result is under the assumption of a two-year GSM service 


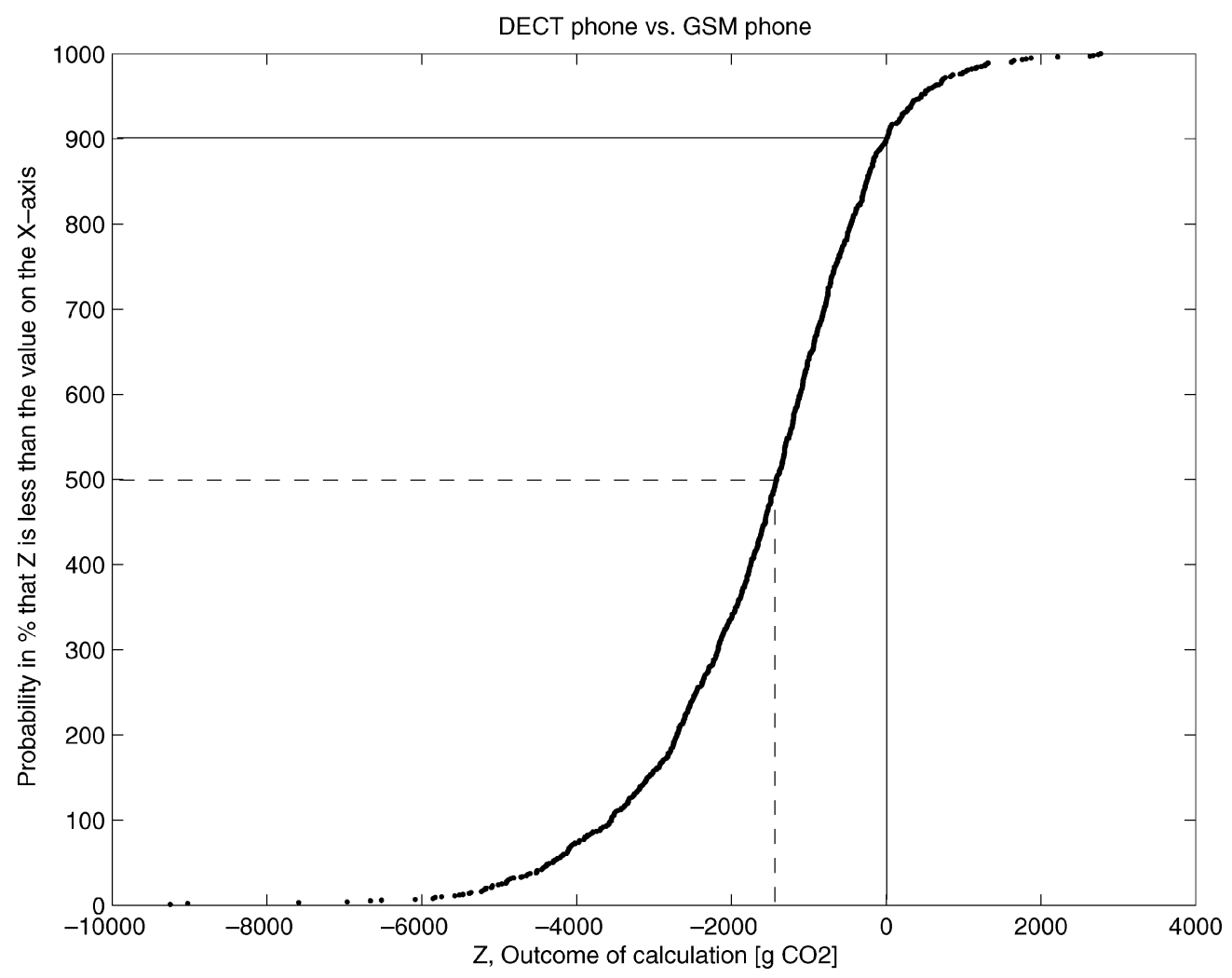

Fig. 6. Cumulative Distribution Functions (CDF) for emission of $\mathrm{CO}_{2}$ difference between DECT and GSM when random errors were added to input parameters. The $\mathrm{Y}$-axis represents the number of random numbers and can, therefore, be interpreted as $\%$. ECPR vs. CL

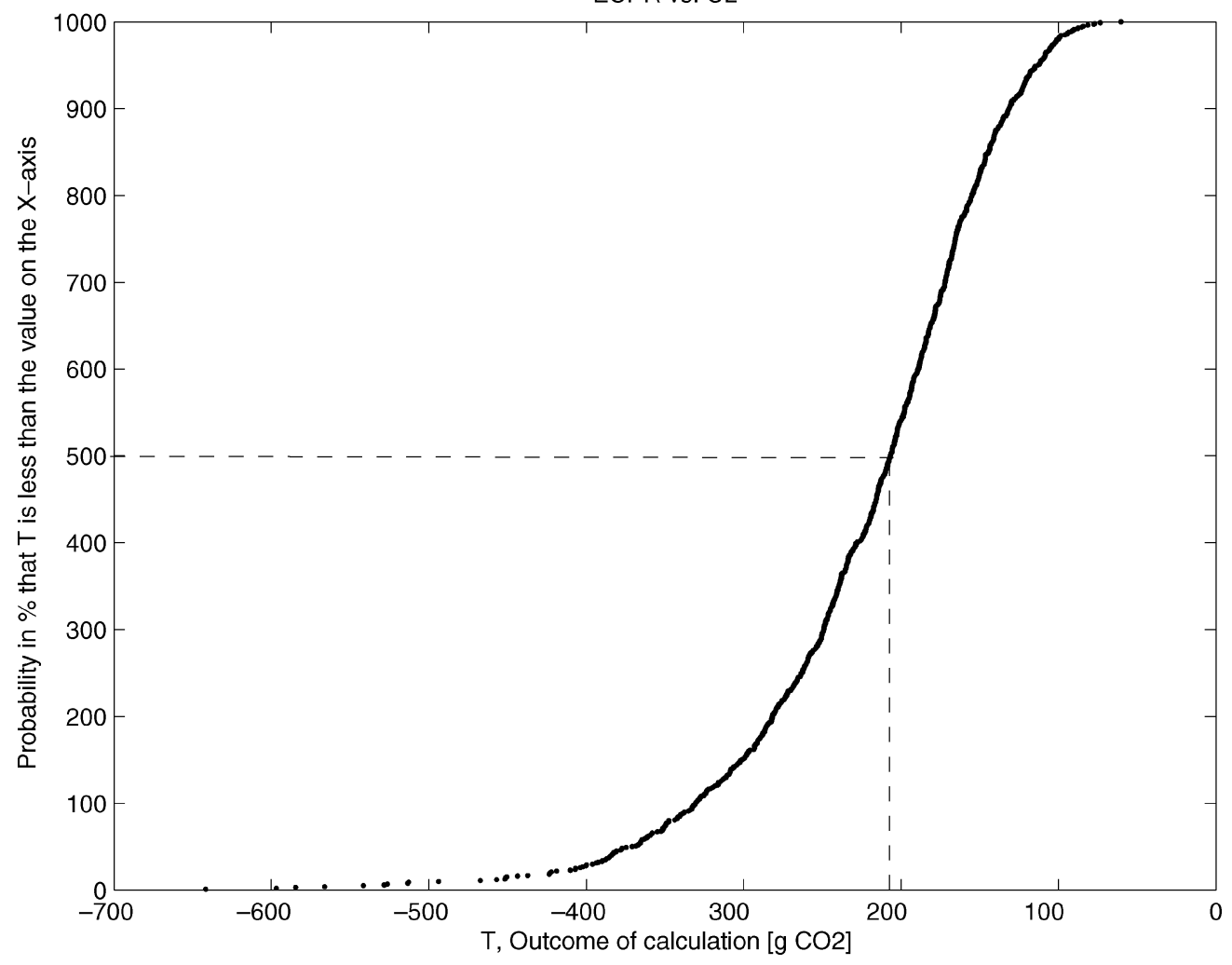

Fig. 7. Cumulative Distribution Functions (CDF) for emission of $\mathrm{CO}_{2}$ difference between ECPR and CL when random errors were added to input parameters. The $\mathrm{Y}$-axis represents the number of random numbers and can, therefore, be interpreted as $\%$.

time and an eight-year DECT service time. From Fig. 7 it is shown that the probability of the ECPR being better than the CL is more than $100 \%$.
The results of the Monte Carlo simulations are shown in Figs. 6 and 7 and the MATLAB codes used to get Figs. 6 and 7 are given in the Appendix, Section IX. 
TABLE III

CAlculation of RElative SENSITIVITy FOR INPUT PARAMETERS IN DECT-GSM APPLICATION

\begin{tabular}{c|c|c|c|c}
\hline Parameter & $\begin{array}{c}\text { Operation to make N-O } \\
=0\end{array}$ & $\begin{array}{c}\text { Critical error } \\
\text { factor (CEF) }\end{array}$ & $\begin{array}{c}\text { Error } \\
\text { factor(EF) } \\
\text { See Table 2 }\end{array}$ & $\begin{array}{c}\text { Relative } \\
\text { sensitivity(EF/CEF) }\end{array}$ \\
\hline A & Multiply by CEF & -2.1177 & 1.2 & 0.57 \\
\hline B1 & Multiply by CEF & 1.8508 & 1.4 & 0.76 \\
\hline B2 & Divide by CEF & 1.8508 & 1.4 & 0.76 \\
\hline C & Multiply by CEF & -1.8812 & 1.3 & 0.69 \\
\hline D & Multiply by CEF & -2.2235 & 1.5 & 0.67 \\
\hline E & Multiply by CEF & 8.5482 & 1.03 & 0.12 \\
\hline F & Multiply by CEF & 7.0573 & 1.01 & 0.14 \\
\hline G & Multiply by CEF & 5.0294 & 1.2 & 0.24 \\
\hline H1 & Multiply by CEF & -3.1699 & 1 & 0.32 \\
\hline H2 & Multiply by CEF & 5.5901 & 1 & 0.18 \\
\hline H3 & Multiply by CEF & 2.5884 & 1 & 0.39 \\
\hline H4 & Divide by CEF & 6.2421 & 1 & 0.16 \\
\hline H5 & Multiply by CEF & 2.5884 & 1 & 0.39 \\
\hline H6 & Divide by CEF & 3.279 & 1 & 0.30 \\
\hline I & Multiply by CEF & -1.0853 & 1.03 & 0.95 \\
\hline J & Multiply by CEF & -1.0583 & 1.01 & 0.95 \\
\hline K & Divide by CEF & -1.264 & 1.2 & 0.95 \\
\hline L1 & Divide by CEF & -1.869 & 1 & 0.53 \\
\hline L2 & Divide by CEF & -1.322 & 1.25 & 0.94 \\
\hline L3 & Divide by CEF & -1.869 & 1 & 0.53 \\
\hline L4 & Divide by CEF & -3.526 & 1.2 & 0.34 \\
\hline
\end{tabular}

TABLE IV

CALCUlation of RElative SENSITIVITY FOR INPUT PARAMETERS IN ECPR-CL APPLICATION

\begin{tabular}{c|c|c|c|c}
\hline Parameter & $\begin{array}{c}\text { Operation to make V-U } \\
=0\end{array}$ & $\begin{array}{c}\text { Critical error } \\
\text { factor (CEF) }\end{array}$ & $\begin{array}{c}\text { Error } \\
\text { factor(EF) } \\
\text { See Table 2 }\end{array}$ & $\begin{array}{c}\text { Relative } \\
\text { sensitivity(EF/CEF) }\end{array}$ \\
\hline ECPR1 & Multiply by CEF & 105.5333 & 1.1 & 0.0104 \\
\hline R & Multiply by CEF & 53.2667 & 1.4 & 0.0262 \\
\hline ECPR2 & Multiply by CEF & 105.5333 & 1.1 & 0.0104 \\
\hline CL1 & Multiply by CEF & -260.3333 & 1.1 & -0.0042 \\
\hline CL2 & Multiply by CEF & -129.6667 & 1.1 & -0.0085 \\
\hline S & Divide by CEF & 66.2252 & 1.4 & 0.02 \\
\hline CL3 & Multiply by CEF & -4.2267 & 1.1 & 0.26 \\
\hline CL4 & Multiply by CEF & -77.4000 & 1.1 & 0.0142 \\
\hline CL5 & Multiply by CEF & -5.5333 & 1.1 & 0.199 \\
\hline CL6 & Multiply by CEF & -25.1333 & 1.1 & 0.043 \\
\hline CL7 & Divide by CEF & -1.3473 & 1.1 & 0.816 \\
\hline CL8 & Multiply by CEF & -103.5333 & 1.1 & 0.0106 \\
\hline CL9 & Multiply by CEF & -33.8444 & 1.1 & 0.0325 \\
\hline
\end{tabular}

\section{A. Sensitivity Analysis}

In order to identify the input data, which contribute most to a low significance, critical error factors (CEF) were calculated. The CEF is the factor by which a certain input data element has to be multiplied in order to make (5) or (6) zero. The results of the DECT/GSM phone calculations for the GSM two-year service time case are shown in Table III and for ECPR/CL in Table IV. The CEF's were calculated using Newton's method and the MATLAB code used is displayed in Appendix, Section IX.

\section{Discussion}

This study is limited, but still demands quite a lot of work. The increase of work with data collection for other components than microcircuits and printed wiring boards could be imagined, if uncertainty would be included for more inventory parameters in the data collection model. Steen's [3] methodology has not been exclusively used, but it is well suited for the present study. For the DECT/GSM study the results reflects the longer service time of the DECT which is an environmental advantage as illustrated by Fig. 8 .

As shown by Fig. 8, if both phones would have the same service time, the GSM would be better than the DECT. The point located at a two-year GSM service time corresponds to the relationship between DECT and GSM shown in Fig. 4. The break-even point is just before a six-year GSM service time.

It could be argued if the assumptions made and narrow system boundaries are appropriate and valid and if another result would have been obtained if more unit processes had been included. For both the DECT phone and the GSM phone, the total silicon chip surface is more uncertain than both the microcircuit weight and the printed board surface layers, but this would not affect the conclusions. If the DECT would have four times as long service time as the GSM it would be an advantage as shown by the electricity/ $\mathrm{CO}_{2}$ calculation in Fig. 8. The sensitivity analysis shows that the amount of GSM hardware; microcircuits weight $(\mathrm{I})$, surface layers of printed board $(\mathrm{J})$, and silicon chip surface (K) contribute most to the significance followed by the GSM 
GSM Service time influence on $\mathrm{CO}_{2}$ emissions

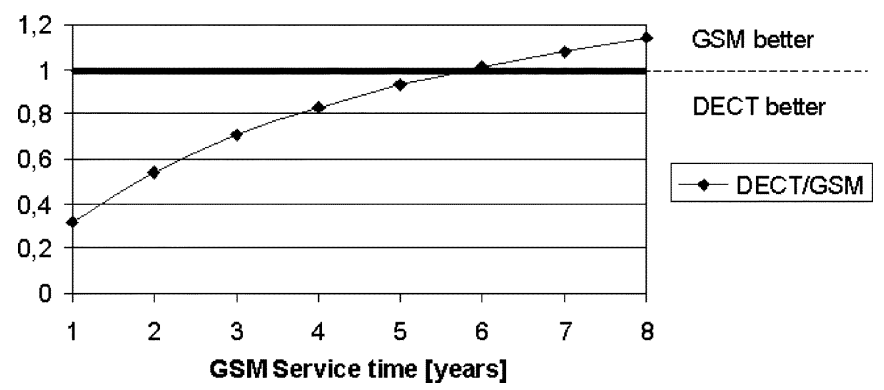

Fig. 8. Dependence of GSM phone service time on $\mathrm{CO}_{2}$ emissions as compared to the DECT phone.

speech time L2. This is due to the two-year GSM phone service time assumed in this sensitivity calculation. If other GSM phone service times are chosen other factors could contribute more. For the ECPR/classical photolithography based microscale metallization (CL) study the results reflects the fewer number of process steps and the lower electricity consumption needed by the ECPR to reach the functional unit. The sensitivity analysis shows that the electricity consumption in the hard-baking step CL7 contributes most to the significance followed by the electricity consumption in the soft-baking step CL3. The difference in results is large enough to be able to draw conclusions, as the processes with the highest electricity consumption within the system boundaries have been determined. Electricity consumption for clean rooms has not been included as it is judged to be the same for ECPR and CL as both processes need clean rooms. The similarity of operating principles for these processes has also been determined.

It has not been investigated how different probability distributions for the input data may affect the results. The DECT/GSM comparison is more uncertain as the difference in the base line result is smaller than the ECPR/CL. Even so it is not realistic the input data uncertainty would be so large that no conclusion could be drawn.

The CL need more process steps to achieve the same result and this research has put a figure to the electricity efficiency of the ECPR. It is doubtful the CL could be better than ECPR if another functional unit would have been chosen, e.g., building more layers or system expansion. Other excluded ECPR environmental aspects are the master electrode manufacturing and other ancillary equipment related manufacturing processes.

\section{CONCLUSION}

A straightforward method to include uncertainty for input LC inventory data based on earlier work has been used to quantify the influence of realistic errors for input data in two electronic applications. When reasonable uncertainty intervals was attached to input data it was established that it is for certain to $100 \%$ probability that the ECPR is better than classical photolithography based microscale metallization (CL) from an electricity point of view within the system boundaries. The assumption that the DECT phone having an eight-year service time was better than a GSM phone having a two-year service time could be verified as well to a $90 \%$ probability. The conclusion is the
ECPR technology is more electricity efficient than CL in producing one layer of copper on a silicon wafer having a diameter of $20.32 \mathrm{~cm}$. The conclusion is that the longer service time of a cordless DECT phone is reflected in an electricity $/ \mathrm{CO}_{2} \mathrm{com}-$ parison with a GSM phone, if use in an office is considered. Reasonable uncertainty intervals used for the input life cycle inventory data for the studied DECT/GSM and ECPR/CL system does affect the outcome of calculation of emission of $\mathrm{CO}_{2}$ but not to the degree that conclusions are not valid.

\section{FURTHER WORK}

The system boundaries may be narrow and if the material consumption figures would be added to the calculation of classical photolithography based microscale metallization (CL)/ECPR processes it should only enhance the advantage of the ECPR, but it would enhance the environmental importance of material consumption and waste generation.

The functional unit discussion is not ended regarding for the DECT/GSM comparison. Different uncertainty intervals and probability distributions could apply for different types of data and the interrelated input data dependence should be investigated.

Today there exist very few life cycle inventory (LCI) data with the range of uncertainty for input and output elements. It must be emphasized that the upcoming LCI databases should be standard deviation characterized just like the Swiss ecoinvent database. [24].

More inventory parameters and probability distributions characteristic for microsystems could be included and error analysis should be applied to future life inventory methodology, especially for future packaging concepts such as system-in-apackage and system-on-a-chip comparisons.

\section{APPENDIX}

In this Appendix , the MATLAB codes to get Figs. 6 and 7 and Tables III and IV are given.

\section{A. MATLAB Code in m-file dg2new to Get Fig. 6}

function dg2new

\%This program makes a graph of the number of random numbers generated from

\%a lognormal distribution versus the dif-

ference in emission of $\mathrm{CO} 2$ between

\%a DECT phone and a GSM phone when random errors are set to the input data.

othe number of random errors on the y-axis can be interpreted as a

\%probability in $\%$. I.e. 500 is the median when 1000 random numbers are

ogenerated. In this scenario the GSM phone has the two-year service time as

ocompared to the DECT phones eight years, and the GSM hardware is replaced $8 / 2$ times.

$\mathrm{A}=\exp ($ normrnd $(\log (51.696), \log (1.2), 1000,1))$; olectricity consumption PWB final assembly 
$\mathrm{B} 1=\exp (\operatorname{normrnd}(\log (132), \log (1.4), 1000,1)) ;$

ஃCO2 emission 1 MJ electricity

$\mathrm{B} 2=\exp ($ normrnd $(\log (132), \log (1.4), 1000,1))$;

○CO2 emission 1 MJ electricity

$\mathrm{C}=\exp ($ normrnd $(\log (0.9453), \log (1.3), 1000,1))$;

olectricity consumption IC final

assembly

$\mathrm{D}=\exp ($ normrnd $(\log (0.0136), \log (1.5), 1000,1))$;

oelectricity consumption IC wafer pro-

cessing per $\mathrm{mm} 2$

$\mathrm{E}=\exp (\operatorname{normrnd}(\log (1.536), \log (1.03), 1000,1))$;

oweight of IC's in DECT phone

$\mathrm{F}=\exp (\operatorname{normrnd}(\log (0.035), \log (1.01), 1000,1))$;

onumber of $\mathrm{m} 2$ *layers in the DECT phone

$\mathrm{G}=\exp ($ normrnd $(\log (200), \log (1.2), 1000,1))$ ；

onumber of $\mathrm{mm} 2 \mathrm{Si}$ in $\mathrm{DECT}$

$\mathrm{H}=\exp ($ normrnd $(\log (18.8568), \log (1.05), 1000,1)) ; \circ \mathrm{MJ}$

electricity for the DECT use phase

H1 = ones $(1000,1)$; \%speech hours per day for

the DECT phone

H2 $=23 *$ ones $(1000,1)$; oidle hours per day for

the DECt phone

H3 $=0.55 *$ ones $(1000,1)$; obattery capacity (Ah)

for DECT

$\mathrm{H} 4=8 *$ ones $(1000,1) ;$ omaximum speech time (h)

for the DECT

H5 $=4.8 *$ ones $(1000,1) ;$ \%voltage $(V)$ for the DECT phone

H6 $=80 *$ ones $(1000,1)$; omaximum standby time

(h) for the DECT phone

$\mathrm{I}=\exp ($ normrnd $(\log (5.56), \log (1.03), 1000,1)) ;$ oweight

of IC's in GSM phone

$\mathrm{J}=\exp ($ normrnd $(\log (0.103), \log (1.01), 1000,1))$;

onumber of $\mathrm{m} 2$ *layers in the GSM phone

$\mathrm{K}=\exp (\operatorname{normrnd}(\log (450), \log (1.2), 1000,1))$; onumber

of $\mathrm{mm} 2 \mathrm{Si}$ in GSM

$\mathrm{L} 1=0.6 *$ ones $(1000,1)$; obattery capacity (Ah)

for GSM

$\mathrm{L} 2=\exp ($ normrnd $(\log (2.9), \log (1.25), 1000,1)) ;$ \% speech

time (h) for the GSM

L3 $=3.6 *$ ones $(1000,1)$; ovoltage (V) for the GSM

phone

$\mathrm{L} 4=\exp (\operatorname{normrnd}(\log (130), \log (1.2), 1000,1))$;

ostandby time (h) for the GSM phone

$\mathrm{Y} 1=152.064 \mathrm{e} 6 *$ ones $(1000,1)$; onumber of seconds

in $220 * 8=1760$ days

$\mathrm{Y} 2=152.064 \mathrm{e} 6 *$ ones $(1000,1) ;$ onumber of seconds in $220 * 8=1760$ days

$\mathrm{Z}=\mathrm{F} . * \mathrm{~A} . * \mathrm{~B} 1-\mathrm{J} . * \mathrm{~A} . * \mathrm{~B} 2+\mathrm{E} . * \mathrm{C} . * \mathrm{~B} 1$

$-\mathrm{I} . * \mathrm{C} . * \mathrm{~B} 2+\mathrm{G} . * \mathrm{D} . * \mathrm{~B} 1-\mathrm{K} . * \mathrm{D} . * \mathrm{~B} 2$

$+\frac{\left(\frac{\mathrm{H} 1 .}{24 .} * \mathrm{H} 3 . * \frac{1 .}{\mathrm{H} 4 .} * \mathrm{H} 5 . * \mathrm{Y} 1+\frac{\mathrm{H} 2 .}{24 .} * \mathrm{H} 3 . * \frac{1 .}{\mathrm{H} 6 .} * \mathrm{H} 5 . * \mathrm{Y} 2\right) .}{1 \mathrm{e} 6 . * \mathrm{~B} 1}$

$-\frac{\left(\frac{\mathrm{H} 1 .}{24 .} * \mathrm{~L} 1 . * \frac{1 .}{\mathrm{L} 2 .} * \mathrm{~L} 3 . * \mathrm{Y} 1+\frac{\mathrm{H} 22}{24 .} * \mathrm{~L} 1 . * \frac{1 .}{\mathrm{L} 4 .} * \mathrm{~L} 3 . * \mathrm{Y} 2\right)}{1 \mathrm{e} 6 . * \mathrm{~B} 2} ;$

$\mathrm{m}=\operatorname{mean}(\mathrm{Z})$
$\mathrm{s}=\operatorname{std}(\mathrm{Z})$;

$\mathrm{k}=\operatorname{median}(\mathrm{Z})$;

$\mathrm{y}=\operatorname{normcdf}(\mathrm{Z}, \mathrm{m}, \mathrm{s})$;

$\mathrm{s}=\operatorname{sort}(\mathrm{Z}, 1)$;

$\mathrm{d}=1: 1000$;

$\operatorname{plot}\left(\mathrm{s}, \mathrm{d},{ }^{\prime} \mathrm{k} .{ }^{\prime}\right)$

title('DECT phone versus GSM phone');

xlabel('Z, Outcome of calculation [ $\mathrm{g}$

CO2]') ; Ylabel ('Probability ino that $\mathrm{Z}$ is

less than the value on the $\mathrm{X}$-axis').

\section{B. MATLAB Code in m-file ec.m to Get Fig. 7}

function ec

oThis program makes a graph of the number of random numbers generated from

\%a lognormal distribution versus the difference in emission of $\mathrm{CO} 2$ between

\%a ECPR compared to classical photolithography

\%based microscale metallization (CL) when random errors are set to the input data. \%The number of random errors on the y-axis can be interpreted as a

oprobability in $\%$. I.e. 500 is the median when 1000 random numbers are \%generated.

CL1 $=\exp ($ normrnd $(\log (6), \log (1.1), 1000,1))$; 。electricity consumption CL photo resist application

CL2 $=\exp ($ normrnd $(\log (12), \log (1.1), 1000,1))$; \&electricity consumption CL photo resist treatment

CL3 $=\exp ($ normrnd $(\log (300), \log (1.1), 1000,1))$ ；

oelectricity consumption CL soft baking

CL4 $=\exp ($ normrnd $(\log (20), \log (1.1), 1000,1))$; \&electricity consumption CL UV light exposure

CL5 $=\exp (\operatorname{normrnd}(\log (240), \log (1.1), 1000,1))$ ；

oelectricity consumption CL prebaking

CL6 $=\exp ($ normrnd $(\log (60), \log (1.1), 1000,1))$; 。elec-

tricity consumption CL development

CL7 $=\exp (\operatorname{normrnd}(\log (900), \log (1.1), 1000,1))$ ；

olectricity consumption hard baking

CL8 $=\exp (\operatorname{normrnd}(\log (15), \log (1.1), 1000,1))$; \%elec-

tricity consumption CL plating

CL9 $=\exp ($ normrnd $(\log (45), \log (1.1), 1000,1))$; 。electricity consumption CL stripping

ECPR1 = exp(normrnd $(\log (15), \log (1.1), 1000,1))$; oelectricity consumption ECPR Cu deposition on master

ECPR2 = $\exp ($ normrnd $(\log (15), \log (1.1), 1000,1))$; olectricity consumption ECPR pressing of master and substrate

$\mathrm{S}=\exp (\operatorname{normrnd}(\log (0.132), \log (1.4), 1000,1)) ; \quad$ 。g CO2 emitted per kJ electricity produced (European average) 
$\mathrm{R}=\exp ($ normrnd $(\log (0.132), \log (1.4), 1000,1)) ; \% \mathrm{~g}$ CO2 emitted per kJ electricity produced (European average)

$$
\begin{aligned}
\mathrm{T}= & \mathrm{ECPR} 1 . * \mathrm{R}+\mathrm{ECPR} 2 . * \mathrm{R}-\mathrm{CL} 1 . * \mathrm{~S} \\
& -\mathrm{CL} 2 . * \mathrm{~S}-\mathrm{CL} 3 . * \mathrm{~S}-\mathrm{CL} 4 . * \mathrm{~S}-\mathrm{CL} 5 . * \mathrm{~S} \\
& -\mathrm{CL} 6 . * \mathrm{~S}-\mathrm{CL} 7 . * \mathrm{~S}-\mathrm{CL} 8 . * \mathrm{~S}-\mathrm{CL} 9 . * \mathrm{~S} ;
\end{aligned}
$$

$\mathrm{m}=\operatorname{mean}(\mathrm{T})$;

$\mathrm{s}=\operatorname{std}(\mathrm{T})$;

$\mathrm{k}=\operatorname{median}(\mathrm{T})$;

$\mathrm{y}=\operatorname{normcdf}(\mathrm{T}, \mathrm{m}, \mathrm{s})$;

$\mathrm{s}=\operatorname{sort}(\mathrm{T}, 1)$;

$\mathrm{d}=1: 1000$;

$\operatorname{plot}\left(\mathrm{s}, \mathrm{d},{ }^{\prime} \mathrm{k} .{ }^{\prime}\right)$

title('ECPR versus CL');

xlabel('T, Outcome of calculation [g CO2]') ; ylabel ('Probability ino that $\mathrm{T}$ is less than the value on the $\mathrm{X}$-axis').

\section{MATLAB Code in m-file nrdgnewa.m to Get the Critical Error Factor for A in Table III}

function nrdgnewa

oThis program calculates the so called critical error factor (CEF) for different oinput parameter values in the equation for Z. The CEF is a measure of the sensitivity

oof a priority between two alternatives to an input parameter value $x$. It

\%is calculated as the ratio of the critical error $\mathrm{dx}$, i.e., variation in $\mathrm{x}$ orequired to change a priority, over the value of $\mathrm{x} . \mathrm{CEF}=\mathrm{dx} / \mathrm{x}$. The

oprogram uses Newton's method as the problem can be seen as finding

oroots to the equation $\mathrm{Z}=0$. The problem can be seen as: By which number does othe input parameter value have to be multiplied to make $\mathrm{Z}=0$ ?

$\mathrm{A}=51.696$;

$\mathrm{B} 1=132$;

$\mathrm{B} 2=132$;

$\mathrm{C}=0.9453$ ；

$\mathrm{D}=0.0136$;

$\mathrm{E}=1.536$ ；

$\mathrm{F}=0.035$;

$\mathrm{G}=200$ ；

$\mathrm{H} 1=1$;

$\mathrm{H} 2=23$;

$\mathrm{H} 3=0.55$;

$\mathrm{H} 4=8$;

$\mathrm{H} 5=4.8$;

$\mathrm{H} 6=80$;

$\mathrm{I}=5.56$;

$\mathrm{J}=0.103$;

$\mathrm{K}=450$;

$\mathrm{L} 1=0.6$;
$\mathrm{L} 2=2.9$ ；

$\mathrm{L} 3=3.6$;

$\mathrm{L} 4=130 ;$

$\mathrm{Y} 1=152.064 \mathrm{e} 6 ;$

$\mathrm{Y} 2=152.064 \mathrm{e} 6$

$\mathrm{N}=\mathrm{F} \cdot * \mathrm{~A} \cdot * \mathrm{~B} 1+\mathrm{E} . * \mathrm{C} \cdot * \mathrm{~B} 1+\mathrm{G} \cdot * \mathrm{D} \cdot * \mathrm{~B} 1$

$$
+\frac{\left(\frac{\mathrm{H} 1 .}{24 .} * \mathrm{H} 3 . * \frac{1 .}{\mathrm{H} 4 .} * \mathrm{H} 5 . * \mathrm{Y} 1+\frac{\mathrm{H} 2 .}{24 .} * \mathrm{H} 3 . * \frac{1 .}{\mathrm{H} 6 .} * \mathrm{H} 5 . * \mathrm{Y} 2\right)}{1 \mathrm{e} 6 . * \mathrm{~B} 1} ;
$$

$\mathrm{O}=\mathrm{J} . * \mathrm{~A} . * \mathrm{~B} 2+\mathrm{I} . * \mathrm{C} . * \mathrm{~B} 2+\mathrm{K} . * \mathrm{D} . * \mathrm{~B} 2$

$$
+\frac{\left(\frac{\mathrm{H} 1}{24 .} * \mathrm{~L} 1 . * \frac{1 .}{\mathrm{L} 2 .} * \mathrm{~L} 3 . * \mathrm{Y} 1+\frac{\mathrm{H} 2 .}{24 .} * \mathrm{~L} 1 . * \frac{1 .}{\mathrm{L} 4 .} * \mathrm{~L} 3 . * \mathrm{Y} 2\right)}{1 \mathrm{e} 6 . * \mathrm{~B} 2} ;
$$

$\mathrm{h}=1 ; \mathrm{x}=2$;

while $\operatorname{abs}(\mathrm{h} / \mathrm{x})>1 \mathrm{e}-5$

$$
\begin{aligned}
\mathrm{Z}= & \mathrm{F} * \mathrm{~A} * \mathrm{x} * \mathrm{~B} 1-\mathrm{J} * \mathrm{~A} * \mathrm{x} * \mathrm{~B} 2+\mathrm{E} * \mathrm{C} * \mathrm{~B} 1 \\
& -\mathrm{I} * \mathrm{C} * \mathrm{~B} 2+\mathrm{G} * \mathrm{D} * \mathrm{~B} 1-\mathrm{K} * \mathrm{D} * \mathrm{~B} 2 \\
& +\frac{\mathrm{H} 1}{24} * \mathrm{H} 3 * \frac{1}{\mathrm{H} 4} * \mathrm{H} 5 * \frac{\mathrm{Y} 1}{1 \mathrm{e} 6} * \mathrm{~B} 1 \\
& +\frac{\mathrm{H} 2}{24} * \mathrm{H} 3 * \frac{1}{\mathrm{H} 6} * \mathrm{H} 5 * \frac{\mathrm{Y} 2}{1 \mathrm{e} 6} * \mathrm{~B} 1 \\
& -\frac{\mathrm{H} 1}{24} * \mathrm{~L} 1 * \frac{1}{\mathrm{~L} 2} * \mathrm{~L} 3 * \frac{\mathrm{Y} 1}{1 \mathrm{e} 6} * \mathrm{~B} 2 \\
& -\frac{\mathrm{H} 2}{24} * \mathrm{~L} 1 * \frac{1}{\mathrm{~L} 4} * \mathrm{~L} 3 * \frac{\mathrm{Y} 2}{1 \mathrm{e} 6} * \mathrm{~B} 2
\end{aligned}
$$

Zprim $=\mathrm{F} * \mathrm{~A} * \mathrm{~B} 1-\mathrm{J} * \mathrm{~A} * \mathrm{~B} 2$;

$\mathrm{h}=\mathrm{Z} /$ Zprim; $\mathrm{x}=\mathrm{x}-\mathrm{h}$

end

\section{MATLAB Code in m-file nrec.m to Get the Critical Error Factor for CL9 in Table IV}

function nrec

oThis program calculates the so called critical error factor ( $\mathrm{CEF}$ ) for different \%input parameter values in the equation for $Z$. The CEF is a measure of the sensitivity

\%of a priority between two alternatives to an input parameter value, $\mathrm{x}$. It

ois calculated as the ratio of the critical error $\mathrm{dx}$, i.e variation in $\mathrm{x}$

orequired to change a priority, over the value of $\mathrm{x}$. $\mathrm{CEF}=\mathrm{dx} / \mathrm{x}$. The

oprogram uses Newton's method as the problem can be seen as finding

oroots to the equation $\mathrm{T}=0$. The problem can be seen as: By Which number does

othe input parameter value have to be multiplied to make $\mathrm{T}=0$ ?

CL1 $=6$;

CL2 $=12 ；$

CL3 $=300 ;$

CL4 $=20$;

CL5 $=240$ ； 


$$
\begin{aligned}
& \text { CL6 }=60 ; \\
& \text { CL7 }=900 ; \\
& \text { CL8 }=15 ; \\
& \text { CL9 }=45 ; \\
& \text { ECPR1 }=15 ; \\
& \text { ECPR2 }=15 ; \\
& \text { S }=0.132 ; \\
& \text { R }=0.132 ;
\end{aligned}
$$

$$
\begin{aligned}
\mathrm{U}= & \mathrm{CL} 1 * \mathrm{~S}+\mathrm{CL} 2 * \mathrm{~S}+\mathrm{CL} 3 * \mathrm{~S}+\mathrm{CL} 4 * \mathrm{~S} \\
& +\mathrm{CL} 5 * \mathrm{~S}+\mathrm{CL} 6 * \mathrm{~S}+\mathrm{CL} 7 * \mathrm{~S}+\mathrm{CL} 8 * \mathrm{~S}+\mathrm{CL} 9 * \mathrm{~S} ;
\end{aligned}
$$$$
\mathrm{V}=\mathrm{ECPR} 1 . * \mathrm{R}+\mathrm{ECPR} 2 . * \mathrm{R} \text {; }
$$

$\mathrm{T}=\mathrm{ECPR} 1 * \mathrm{R}+\mathrm{ECPR} 2 * \mathrm{R}-\mathrm{CL} 1 * \mathrm{~S}-\mathrm{CL} 2 * \mathrm{~S}-\mathrm{CL} 3 * \mathrm{~S}$ $-\mathrm{CL} 4 * \mathrm{~S}-\mathrm{CL} 5 * \mathrm{~S}-\mathrm{CL} 6 * \mathrm{~S}-\mathrm{CL} 7 * \mathrm{~S}-\mathrm{CL} 8 * \mathrm{~S}-\mathrm{CL} 9 * \mathrm{~S}$;

$\mathrm{h}=1 ; \mathrm{x}=2$;

while $\operatorname{abs}(\mathrm{h} / \mathrm{x})>1 \mathrm{e}-5$

$\mathrm{T}=\mathrm{ECPR} 1 * \mathrm{R}+\mathrm{ECPR} 2 * \mathrm{R}-\mathrm{CL} 1 * \mathrm{~S}-\mathrm{CL} 2 * \mathrm{~S}-\mathrm{CL} 3 * \mathrm{~S}$ $-\mathrm{CL} 4 * \mathrm{~S}-\mathrm{CL} 5 * \mathrm{~S}-\mathrm{CL} 6 * \mathrm{~S}-\mathrm{CL} 7 * \mathrm{~S}-\mathrm{CL} 8 * \mathrm{~S}-\mathrm{CL} 9 * \mathrm{X} * \mathrm{~S}$;

Tprim $=-\mathrm{CL} 9 * \mathrm{~S} ;$

$\mathrm{h}=\mathrm{T} /$ Tprim; $\mathrm{x}=\mathrm{x}-\mathrm{h}$

end

\section{ACKNOWLEDGMENT}

The authors would like to thank B.-O. Johansson, Dr. D. R. Andersson, Lic.Eng., R. Rörgren, and Prof. T. Ekvall for useful comments.

\section{REFERENCES}

[1] A. Andræ, "Development of a generic data collection model and environmental assessment of upstream processes for electronic products," Licentiate, Dept. Mech. Eng., Chalmers Univ. Technol., Gothenburg, Sweden, 2002

[2] J. R. May and D. J. Brennan, "Application of data quality assessment methods to an LCA of electricity generation," Int. J. Life Cycle Assessment, vol. 8, no. 4, pp. 215-225, 2003.

[3] B. Steen, "On uncertainty and sensitivity of LCA-based priority setting," J. Cleaner Prod., vol. 5, no. 4, pp. 255-262, 1997.

[4] Patent SE0 102 144-3 and PCT/SE02/01 179.

[5] D. W. Pennington, G. Norris, T. Haagland, and J. C. Bare, "Environmental comparison metrics for life cycle impact assessment and process design," Environ. Progress, vol. 19, no. 2, pp. 83-91, 2000.

[6] E. Regnier and W. F. Hoffman III, "Uncertainty model for product environmental performance scoring," in Proc. IEEE Int. Symp. Electronics and the Environment, 1998, pp. 207-212.

[7] P. A. Sandborn and C. F. Murphy, "A model for optimizing the assembly and disassembly of electronic systems," IEEE Trans. Electron. Packag. Manuf., vol. 22, no. 2, pp. 105-117, Apr. 1999.

[8] D. Kennedy, D. Montgomery, and B. Quay, "Data quality. Statistic environmental life cycle assessment modeling," Int. J. Life Cycle Assessment, vol. 1, no. 4, pp. 199-207, 1996.

[9] A. Ciroth, "Fehlerrechnung in ökobilanzen," Ph.D. dissertation, Technische Univ., Prozesswissenshaften, Berlin, Germany, 2001

[10] B. Maurice, R. Frischknecht, V. Coelho-Schwirtz, and K. Hungerbuhler, "Uncertainty analysis in life cycle inventory. Application to the production of electricity with French coal power plants," J. Cleaner Prod., vol. 8 , no. 2, pp. 95-108, 2000.
[11] G. W. Sonnemann, M. Schuhmacher, and F. Castells, "Uncertainty assessment by a Monte Carlo simulation in a life cycle inventory of electricity produced by a waste incinerator," J. Cleaner Prod., vol. 11, no. 3, pp. 279-292, 2003.

[12] R. Heijungs, "Identification of key issues for further investigation in improving the reliability of life cycle assessments," J. Cleaner Prod., vol. 4, no. 3, pp. 159-166, 1996.

[13] "Environmental management—life cycle assessment—goal and scope definition and inventory analysis," International Organization for Standardization, Genève, Switzerland, ISO 14 041:1998(E), 1998.

[14] B. Ram, A. Stevels, H. Griese, A. Middendorf, J. Müller, N. F. Nissen, and H. Reichl, "Environmental performance of mobile products," in Proc. IEEE Int. Symp. Electronics and the Environment, 1999, pp. 140-145.

[15] M. Schäfer and R. Arenz, "Life cycle inventory results for cordless phone gigaset 2010," presented at the Proc. Environmental Impact of Telecommunication System and Services: 13th Discussion Forum on Life Cycle Assessment, Lausanne, Switzerland, Apr. 25, 2001.

[16] "The Eco-Indicator 99: A Damage Oriented Method for Life Cycle Impact Assessment, Methodology Report," Pré Consultants, Amersfoort, The Netherlands, 2nd ed., 2000.

[17] R. A. Adams, Calculus - A Complete Course. Reading, MA: AddisonWesley, 1991, pp. 220-221.

[18] A. Andræ, U. Östermark, and J. Liu, "Life cycle assessment of a telecommuncations exchange," J. Electron. Manuf., vol. 10, no. 3, pp. $147-160,2000$.

[19] National Office of Pollution Prevention, "Understanding the environmental aspects of electronic products: A life cycle assessment case study of a business telephone," Toxics Pollution Prevention Directorate, Ottawa, ON, Canada, 2000.

[20] "Technical data sheet for GSM phone," Siemens, Siemens S35i, 2003.

[21] "Technical data sheet for DECT phone," Ascom, Ascom 9d24, 2003.

[22] P. Möller and P. Wiwen-Nilsson, "ECPR-electrochemical pattern replication," M.S. thesis, Lund Inst. Technol., Lund, Sweden, 2002.

[23] Nordic Port AB, "Foundations of Ecolab, Varbergsgatan 2C," SE-41265, Gothenburg, Sweden, http://www.port.se.ecolab, Jan. 25, 2000.

[24] G. Rebitzer and R. Frischknecht, "Ecoinvent - A comprehensive web-based life cycle assessment database," in Proc. $\ln L C A / L C M$ 2003, Seattle, WA, Sept. 22-25, 2003.

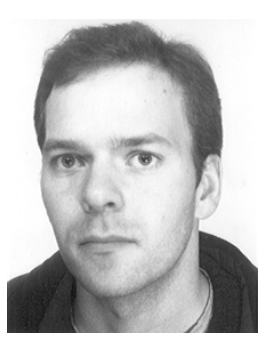

Anders S.G. Andræ received the M.Sc. degree in chemical engineering from the Royal Institute of Technology, Stockholm, Sweden, in 1997, and the Licentiate of Engineering degree from Chalmers University of Technology, Gothenburg, Sweden, in 2002, where he is currently working toward the Ph.D. degree.

He worked for Ericsson with LCA between 1997 and 2001. His speciality is the application of environmental assessment methodologies to microelectronics, and he has previously published five conference papers and three peer-reviewed journal papers in the Journal of Electronics Manufacturing, the International Journal of Life Cycle Assesment, and the Journal Of Electronics Packaging.

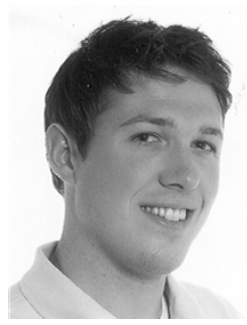

Patrik Möller recieved the M.Sc. degree in chemical engineering from Lund Institute of Technology, Lund, Sweden, in 2002. During his studies, he specialized in micro- and nanotechnology as a scholar at the University of California, Berkeley, in 2000-2001. He is currently working toward the $\mathrm{Ph} . \mathrm{D}$. degree at the Royal Institute of Technology, Stockholm, Sweden, in the laboratory of Solid State Devices.

He is one of the founders of Replisaurus Technologies, Kista, Sweden, a technology startup commercialising the ECPR technology. He has several Swedish and international patents pending.

Dr. Möllers' M.S. thesis project "ECPR-Electrochemical Pattern Replication" was awarded the Telecom City Prize for the best thesis within electronics production in Sweden (2002). 


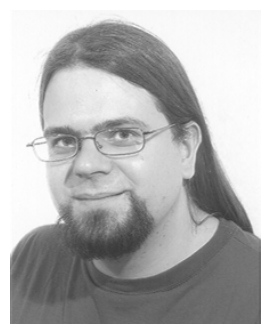

and conferences.

Dr. Anderson is also the Secretary of IEEE-CPMT Sweden as well as the Scandinavian Chapter.
Johan Anderson received the M.Sc. degree in physics from Gothenburg University, Gothenburg, Sweden, in 1997, and the Ph.D. degree in electromagnetic field theory from Chalmers University of Technology, Gothenburg, Sweden, in 2002.

Since 2002, he has been associated with the Division for Electronics Production as an Assistant Professor, where he has worked with thermal management problems in microsystems and self alignment properties of solder joints during reflow soldering. $\mathrm{He}$ has published around 20 papers in refereed journals

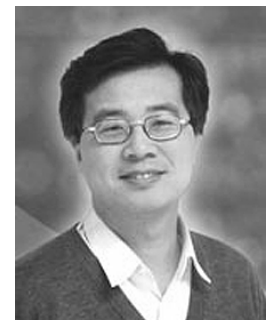

Johan Liu (M'92-SM'96) received the M.S. degree in materials science and the Ph.D. degree in the area of rapid solidification processes of metallic wires, both from the Royal Institute of Technology, Stockholm, Sweden, in 1984 and 1989, respectively.

Between 1989 and 1999, he was with IVF, The Swedish Institute of Production Engineering Research. Since April 1999, he has been a Chair Professor in electronics production at Chalmers University of Technology, Sweden. He also serves as a Director for the Sino-Swedish Microsystem Integration Technology (SMIT) Center in China and Sweden. He has published over 170 papers in refereed journals and conferences, edited a book on conductive adhesives in electronics packaging.

Dr. Liu serves as the Associate Editor for the IEEE TRANSACTIONS ON Component Packaging and Manufacturing TeChNology and as a Member of the International Advisory Committee for the journal Soldering and Surface Mount Technology and a number of advisory conference committees throughout the world. He is the Founding Chair of the IEEE CPMT Sweden, as well as the Scandinavian Chapter. He is also the Founder of the IEEE International Conference Series on Adhesives and Coatings in Electronics Manufacturing (Adhesives in Electronics Series) and Polymeric Electronics Packaging (PEP series) and High Density Packaging series. He is a Member of IMAPS Nordic Chapter. He has served on the Board of Governors for the IEEE CPMT Society since 2001, and received the 2004 IEEE CPMT Society "Exceptional Technical Achievement Award." 